\section{MRS Calls for Nominees for Outstanding Young Investigator Award for 1996}

The Materials Research Society is accepting nominations for the Outstanding Young Investigator Award to be announced at the 1996 MRS Spring Meeting in San Francisco. The award is intended to recognize outstanding, interdisciplinary scientific work in materials research by a young scientist or engineer. The recipient must also show exceptional promise as a developing leader in the materials area.

The award consists of a $\$ 2,000$ cash prize, a presentation trophy bearing a brief citation, and a certificate. Reasonable travel expenses to attend the Spring Meeting and the registration fee will be reimbursed.

Previous recipients are Stuart S.P. Parkin (IBM) for contributions in new materials, high $T_{c}$ superconductors, and magnetic multilayers displaying oscillatory exchange coupling; David D. Awschalom (University of CaliforniaSanta Barbara) for contributions to the physics of molecules in confined geometries, magnetic superlattices, and nanometer-scale magnets; Charles M. Lieber (Harvard University) for contributions to the understanding of novel materials through synthesis and elegant determination of complex local structure and electronic properties; David J. Eaglesham (AT\&T Bell Laboratories) for creativity, leadership, and experimental ingenuity in discovering and understanding fundamental interface, surface, and defect phenomena in semiconductor crystal growth; and A. Paul Alivisatos (University of California-Berkeley) for leadership in materials research, notably in the field of nanocrystals (see Alivisatos's edited transcript of his 1995 MRS Spring Meeting presentation in this issue).

The deadline for submission of nominations is October 1, 1995. For guidelines and application forms, contact John B. Ballance, Executive Director, Materials Research Society, 9800 McKnight Road, Pittsburgh, PA 15237-6006; (412) 367-3003; fax (412) 367-4373. MRIS

\section{DON'T EXPERIMEN T WITH YOUR MAG NETOMETER.}

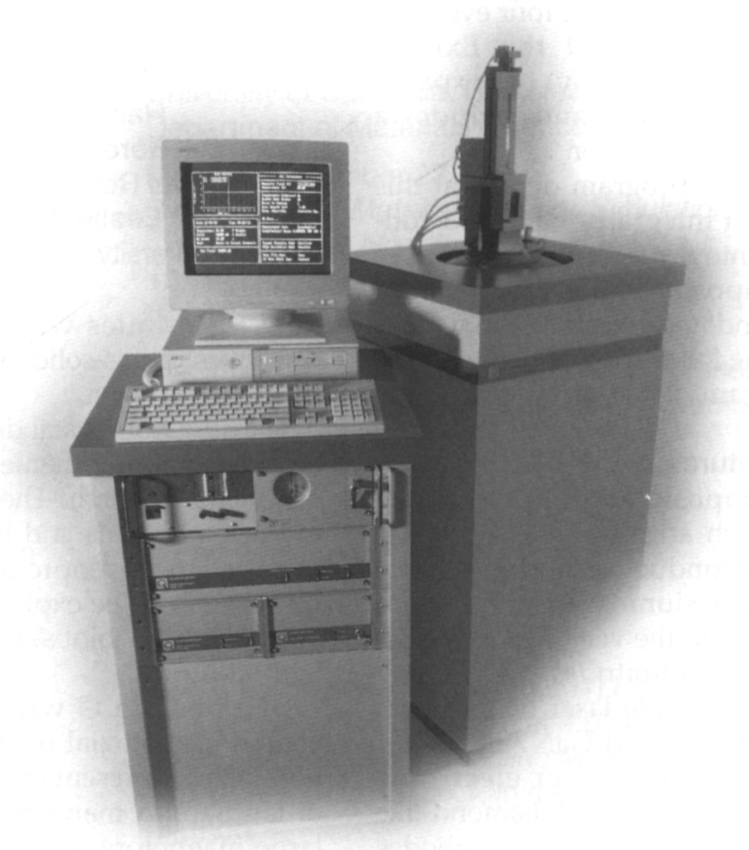

Magnetic Property Measurement System

Proven Technology

Whether it's high-volume characterization of superconductors, high-sensitivity studies of magnetic materials or any other critical magnetic measurement, it's important to have absolute confidence in the accuracy of your results. Which is why so many of the world's most respected labs have come to rely on the Magnetic Property Measurement System (MPMS) from Quantum Design.

\section{SQUID Sensitivity Using Quantum's reliable, time-tested} SQUID (Superconducting QUantum Interference Device) technology, the MPMS can resolve dc magnetic moment changes as small as $10^{-8}$ EMU and as large as 300 EMU. This unsurpassed sensitivity and large dynamic range, combined with patented, fully automated temperature control, have helped make the MPMS the industry standard for magnetic research. So why trust your research to an unproven system? The MPMS is backed by years of experience, thousands of successful experiments, and Quantum's proven commitment to customer service. Call today for a free brochure.

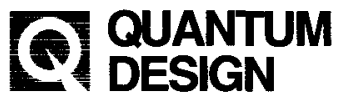




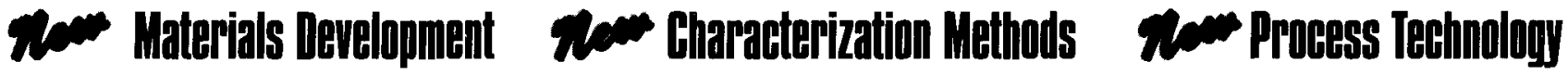

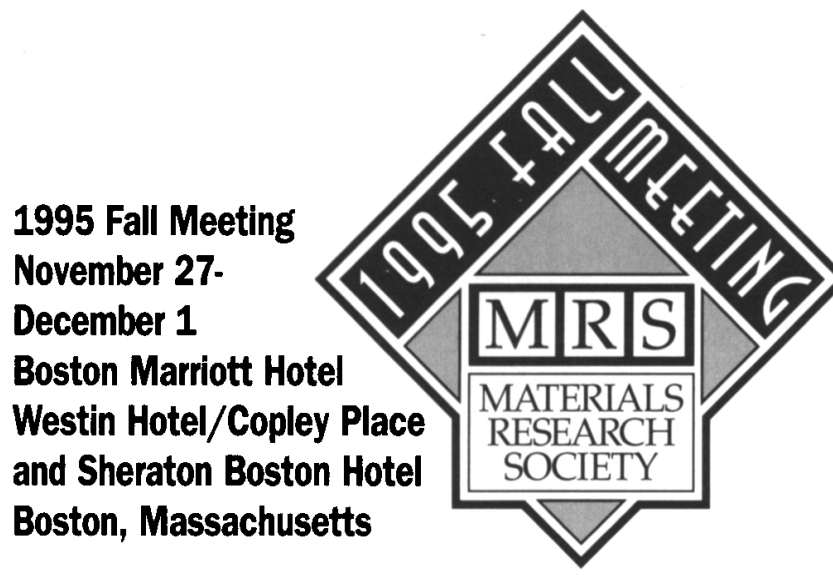

\section{TECHNICAL PROGRAM \\ Symposia}

AAA: Gallium Nitride and Related Materials

A: Ion-Solid Interactions for Materials Modification and Processing

B: Advanced Laser Processing of Materials - Fundamentals and Applications

C: Thermodynamics and Kinetics of Phase Transformations

D: Evolution of Epitaxial Structure and Morphology

E: Metastable Metal-Based Phases and Microstructures

F: Defects in High-Temperature Superconductors - Characterization and Relations to Processing and Properties

G: Epitaxial Oxide Thin Films II

H: Silicide Thin Films - Fabrication, Properties, and Applications

I: $\quad$ Polycrystalline Thin Films II - Structure, Texture, Properties and Applications

J: In-Situ Electron and Tunneling Microscopy of Dynamic Processes

K: Surface/Interface and Stress Effects in Electronic Material Nanostructures

L: Diagnostic Techniques for Semiconductor Materials Processing

M: Disordered Materials and Interfaces -Fractals, Structure, and Dynamics

N: Complex Fluids

O: Self-Assembling Materials and Structures

P: $\quad$ Materials Theory, Simulations, and Parallel Algorithms

Q: $\quad$ Fracture - Instability Dynamics, Scaling, and Ductile/Brittle Behavior

R: Mechanisms of Chemical Degradation of Cement-Based Systems

S: $\quad$ Covalent Ceramics III -Science and Technology of Non-Oxides

T: Electrically Based Microstructural Characterization

U: Materials Inspired by Biology

V: Scientific Basis for Nuclear Waste Management XIX

W: Electrical, Optical, and Magnetic Properties of Organic Solid State Materials

X: Frontiers of Materials Research

$Y: \quad$ Long-Term Performance Issues in Polymers - Chemistry and Physics

Z: Thin Films and Surfaces for Bioactivity and Biomedical Applications

AA: Low-Cost Manufacturing of Materials

BB: Metal-Organic Chemical Vapor Deposition of Electronic Ceramics II

CC: Spectroscopy of Heterojunctions

DD: Diamond for Electronic Applications

EE: Optoelectronic Materials - Ordering, Composition Modulation, and Self-Assembled Structures

FF: Fullerenes, Buckytubes, and Related Materials-Science and Applications

GG: Decomposition, Combustion, and Detonation Chemistry of Energetic Materials

\section{TUTORIAL PROGRAM}

The Materials Research Society is offering its outstanding Tutorial Program at the 1995 Fall Meeting. Up-to-date courses on the latest advances in the materials sciences and engineering complement the Fall Meeting symposium topics. Designed with something for everyone in research, development or processing of materials, the courses include overview presentations, in-depth instruction in specialty and emerging areas, and practical discussions for problem solving, all taught by instructors who are experts in their fields. Class sizes are limited. Early preregistration is encouraged.

\section{EXHIBIT}

An MRS exhibit at the 1995 Fall Meeting will be conveniently located near the technical session rooms. Features include the latest analytical and processing equipment, and publications, which closely parallel the nature of the technical symposia. For information, contact Mary E. Kaufold, Manager, Advertising and Exhibits, Materials Research Society, 9800 McKnight Road, Pittsburgh, PA 152376006; Telephone (412) 367-3004, ext. 541; Fax (412) 367-4373.

\section{PROCEEDINGS}

Many symposia from this meeting will publish proceedings. MRS members and meeting attendees may purchase copies of the proceedings at special prepublication prices and receive priority shipment upon publication. Prices will be higher following the meeting. To take advantage of these special prices, order your proceedings while registering for the meeting. For information on nonmember proceedings prices and ordering procedures, contact the MRS Publications Department

\section{SYMPOSIUM AIDE OPPORTUNITIES}

Graduate students who plan to attend the 1995 Fall Meeting in Boston and are willing to assist in the symposium presentations by operating audio-visual equipment are encouraged to apply for a Symposium Aide position. MRS will pay the 1995 Fall Meeting student registration fee (which includes complimentary student membership through December 1996), and a small stipend toward expenses, for symposium aides who work a minimum of four full half-day sessions. To request an application form and/or information, please contact MRS Headquarters, (412) 367-3004, X-302, Fax (412) 367-4373, E-mail: info@mrs.org.

\section{JOB PLACEMENT}

A Job Placement service will be offered to MRS members and meeting attendees during the 1995 Fall Meeting of the Materials Research Society. The center will be located in the Boston Marriott Hotel/Copley Place (times and dates to be announced later). Individuals using the interviewing facilities at the Materials Research Society Fall Meeting must register for the meeting, as well as with the Job Placement Center. You need not attend, however, to have your resume included on file.

For general meeting information or to request a Call for Papers booklet, a detailed 1995 Fall Meeting program, or information on short courses, publications, exhibit, job placement, or symposium aides, contact:

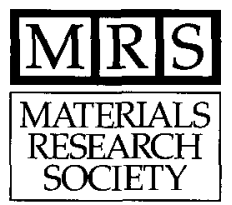

MATERIALS RESEARCH SOCIETY 9800 McKnight Road Pittsburgh, PA 15237-6006 Telephone (412) 367-3004 Fax (412) 367-4373

E-mail: info@mrs.org.

The MRS 1995 Fall Meeting will serve as a key forum for discussion of interdisciplinary leading-edge materials research from around the world. Various meeting formats oral, poster, round-table, forum and workshop sessions are offered to maximize participation. 